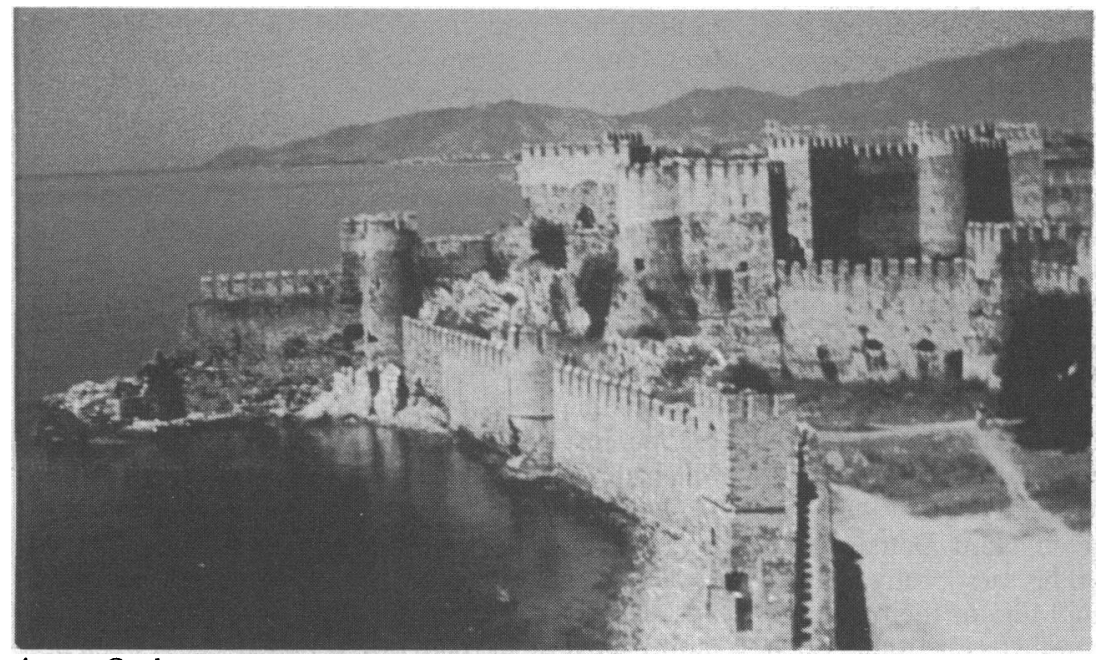

Anamur Castle

goodbye to the enormously helpful doctor, who had to return to his ship and advise my wife, I was put into a five bed ward, with more painkillers for supper.

\section{Black market nursing}

Next day my wife arrived with our luggage and more assurances that everything would be looked after, medically and financially, by the cruise company. The English speaking surgeon then told us about the hospital regime. The main item was that the hospital would provide medical and surgical treatment but everything else was the responsibility of the patient and his family. So nursing care, day and night, would fall on my wife. So where could she be accommodated? A hard kitchen chair by each bed was indicated. Further, my wife must buy in the town $(15 \mathrm{~km}$ away, where the agent had found her a modest hotel) medicines (a list was produced), washing materials such as basin and towel, and soap, and any food and drink beyond the basic, unappetising one course meals brought round on a trolley in the corridor. Bed, bedpan, and urine bottle were the only facilities provided by the hospital. The black market, however, resolved this impossible situation for us elderly folk without contacts within hundreds of kilometres: one of the few day nurses from the operating theatre volunteered to add night shifts to her duties for a moderate fee. This she did, cheerfully and conscientiously, on the hard chair for 10-12 hours on each of five nights. A sweet girl with limited English, she would jump up at each movement I made. My wife did the daytime nursing but also had to spend many frustrating hours in the town getting money, buying medicines and washing equipment, telephoning home, and chasing the rather elusive agent to arrange our return-all with great difficulties of communication. She needed all the patience and inventiveness she could muster, while I could do nothing but remain passively in bed awaiting events.

A Turkish hospital ward is a kind of community centre, each patient surrounded by family and friends operating in shifts. Some would come around to survey the only foreigner with amiable curiosity, offering sweets or mineral water. Conversations, however, were limited to "Hello! How are you?" Communication was indeed a major problem. The idea that "everyone knows English" (or French or German) is just untrue. Apart from the surgeon, the nurse, and the shipping agent our only linguistic contact was an ambulatory patient - a schoolteacher of English - who proved an invaluable friend with whom, as with the nurse, we remain in correspondence.

The prosthesis was inserted as promised three days after admission. Judged by the fairly smooth recovery and by examination at home it was all very efficiently performed. Three days after the operation we were flown home, with stretcher and ambulance, all covered by the lifesaving insurance. There followed three weeks in the relative luxury of NHS wards at home and not too rigorous physiotherapy.

A moral for accident prone travellers: go with a devoted companion; have good travel insurance; keep with the group; brush up your Turkish - and watch your step in the dark.

\title{
Rheumatology in Rasiguères, 1989
}

\section{John A Mathews}

As I had let it be known in advance that I intended to conduct a rheumatological survey during my visit to the ninth "Festival de la Musique et du Vin" in Rasiguères it was no surprise that the visit turned out to be something of a busman's holiday, or rather a rheumatologist's romp. The main study population was to be the body of the orchestra, particularly its upper portion, and my wife was to be research organiser, record keeper, food and wine taster, and, in the event, physiotherapist.

The flight to Montpelier was not without interest. We had to meet the Welsh tenor soloist who would share our hired car to the small village in the Pyrenees. I could not imagine how we would locate him, but identification turned out to be easy. The cabin steward, who had been briefed, duly identified him as the only male passenger of rotund build brandishing the British banknote that features Florence Nightingale.

I learnt on the three hour journey that a singer's sang froid on stage can be offset by sang chaud off it. The soloist's image of his width made him feel at risk of injury as I inadvertently cut corners driving the left hand drive car on the right side along the narrow roads. I also learnt that most singers with valuable instru- ments have them checked every six months by a throat specialist - not for arthritis of the cricoarytenoid joints but for node formation.

We arrived in time to hear a recital by Victoria de los Angeles in the main concert venue, the vaults. This whetted our appetite for the first full scale musical event that took place in the village church: a liturgical performance of Haydn's Nelson Mass. The Manchester Camerata, the festival's orchestra, consisted of 28 players and continuo and we were able to work out roughly how the survey was to be organised. But before I had left the church to contemplate lunch I was called back by the orchestra's travelling consultant physician to deal with a mundane sounding trumpeter's knee.

\section{Trumpeter's knee}

The history immediately indicated the fascination of the problem. The 23 year old Scots born trumpeter had been on tour in India when he and 20 other members of the orchestra were smitten with diarrhoea after eating chicken at the Oberoi Hotel in Delhi (where a group from the Royal College of Physicians of London was entertained by the Association of Physicians of India in

\section{London SE1 7EH}

John A Mathews, FRCP consultant physician

BrMed J 1989;299:1594-5

$$
\text { VOLUME } 299
$$


January). No follow up was available on the other 20, but Gavin developed iritis a few weeks later and mild low back stiffness soon afterwards. As chance would have it, I was equipped with one syringe, one needle, and an ampoule of methylprednisolone acetate $(2 \mathrm{ml}$, $80 \mathrm{mg}$ ). The patient was laid on the front pew (see figure), the skin cleansed with holy water, and $40 \mathrm{ml}$ of viscous yellow synovial fluid aspirated into a libation cup which was borrowed from the vestry. The fluid bore a suspicious resemblance to whisky. The steroid was injected, a pair of crutches was produced by my physiotherapist assistant, and the patient started his indomethacin soon after. Fortunately, he showed no reluctance to imbibe plenty of fluids. Thus began the survey.

Rasiguères has a population of 150 , its most famous resident being the founder of the festival, Moura Lympany. The village is surrounded by low mountains and vineyards, and I understood for the first time the inspiration for her crashing chords and the limpid quality of her scale passages. Geographical compactness helped us to plan the logistics of the survey. Players were interviewed and examined after the morning recital, during the noon open air concert in the village square, or in the lunch marquee. This last venue ensured that we were always on the spot to be invited to lunch with the artists. A few consultations took place by the open air pool in the garden of the festival administrator's house, a bonus in the scorching afternoon heat.

All major events were held in the vaults, which made a fine venue. It resembled a cathedral but was dedicated to Bacchus. The long, narrow central nave was flanked by aisles occupied by vats, the choir was a raised platform for the performers, and behind this the presbytery served as a green room. The north transept was occupied by a large apparatus which I took to be a sterile twentieth century mechanical substitute for pedobaric grape crushing. The nave was occupied by 30 rows of seats, seven chairs wide. The flat sided vats were alleged to enhance the acoustics. Their contents, all 20000 hectolitres, certainly enhanced the appreciation of the music.

\section{Bacchanalian libations}

Each evening concert started at 9 pm and was preceded and punctuated by Bacchanalian libations all from the vaults. Most guests concentrated on the rosé or the dry muscat as a short experiment with the sweet muscat had revealed its somnolent properties. Dinner after the concert was a feast for performers and guests in the large marquee, and generally lasted until two or

An ecclesiastical knee aspiration

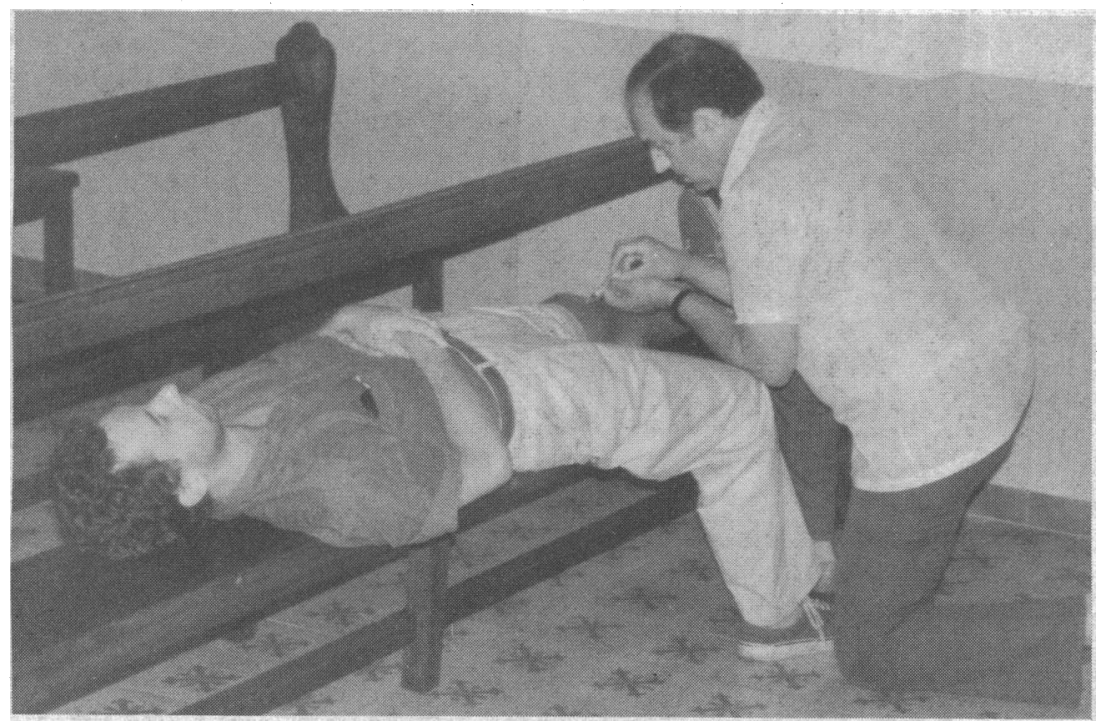

three in the morning. It could be injudiciously followed by a dip in the pool, sometimes unintentional.

The second evening concert was given by a visiting Portuguese pianist. I was called in to confirm his prevailing diagnosis of gout. Despite the etymological innuendos, the traditional association of port and podagra and his origins in the Iberian peninsula failed to concentrate the disorder into his left foot. Happily, his recital was easily sustained by the ailing right foot, aided by my substitution of indomethacin for the poor non-steroidal anti-inflammatory drug prescribed on his last visit to London. Until that evening I had not appreciated that with suitable lubrication of performer and audience even the percussive piano can simulate vibrato.

Now for the academic part of the survey. All the players were asked to estimate how much they played and the age at which they started. They were asked if they had symptoms related to the neck, shoulder girdle, or arms, and these parts were examined from a rheumatological viewpoint. The 29 musicians were aged 22 to 63 (mean 34), and had started playing their chosen instrument between the ages of 5 and 19. They claimed to play an estimated 60 to 2100 hours each year and seeing the enthusiasm the upper figure failed to strain my credulity. Eighteen players had symptoms in the neck, shoulder girdle, or arms which could be related to their occupation. In 11 players the symptoms clearly derived from the cervical spine; in one violinist, interestingly, this occurred only when playing a baroque instrument - that is, without the modern chin and shoulder rests.

Although I elicited no symptoms of the thoracic inlet syndrome, in 15 of the players there was diminution of one or both radial pulses when they braced the shoulders backwards or when I exerted downward traction on the arm. This was much commoner on the left side, but I wonder whether this would be the case in a control group. Two players had shoulder and three had elbow symptoms, but only two had finger problems. One violinist had developed lasting pain and swelling of the index and middle knuckles of the right (bowing) hand after playing Schubert's 9th Symphony. This seems to require about one million movements of the bowing arm, mainly in the last movement, and here may be the first reported case of " $\mathrm{C}$ major synovitis."

\section{Diagnosis on the dining table}

Several players volunteered low back symptoms, often blaming poorly designed orchestral seating. But this did not explain my second rheumatological emergency - the taller than average woman oboist who developed a lumbar disc prolapse, sciatica, and palsy of the fifth lumbar nerve root-diagnosed on a dining table. She had to be rested, corsetted (the appliance loaned from a shorter than average woman), and flown home. (My kit did not contain the requisite epidural but will next time.)

The experiences confirmed my previous opinion that musicians are subjected to physical as well as mental stress. Much background aggravation can be avoided by attention to comfort and posture and an encouraging flattering environment. Systems of posture and faith, such as the Alexander technique had helped, sometimes dramatically. The local problems are often quite definable on routine medical orthopaedic principles and can be avoided by adjustments in technique or local treatments. Kindness, patience, sympathy, and practical experience are needed from the medical advisers. No evidence came to light to support the view that flexion of the elbow with the hand suitably laden produces any directly deleterious effects. But it certainly enhanced communication between performer and audience. Perhaps this is the main message. 